\title{
ART OF TYEB MEHTA
}

\section{तैयब मेहता की कला}

\author{
Kulvendar Kaur 1, Dr. Anjali Pandey 2 四 \\ ${ }^{1}$ Researcher, Government Maharani Lakshmibai Girl P.G. (Autonomous) College, Bhopal, India \\ ${ }^{2}$ H.O.D., Drawing \& Painting Goverment Maharani Lakshmibai Girl P.G.(Autonomous) College, \\ Bhopal, India
}

DOI: https://doi.org/10.29121/granthaalayah.v9.i3.2021.3783

Article Type: Research Article

Article Citation: Kulvendar Kaur, and Dr. Anjali Pandey. (2021). ART OF TYEB MEHTA. International Journal of Research GRANTHAALAYAH, 9(3), 347-352. https://doi.org/10.29121/granthaalayah.v9.i3.2021.3783

Received Date: 8 March 2021

Accepted Date: 31 March 2021

\begin{abstract}
English : Most of the paintings of internationally renowned painter and sculptor Tyeb Mehta, honored with Kalidas and Padma Bhushan, have been influenced by many incidents in the childhood, Edward Munsch and Kokoshka had a great influence on Tyeb, born in Kheda, Gujarat, in his art style from time to time. But change is seen. In the initial paintings, the expression has been given space, in the medium level pictures, the expression of the space has been replaced by the bifurcated two- dimensional picture and the empty space, the diagonal took its place in the final pictures, under which started drawing pictures in triangles. With festivals, Kali, etc., he was counted among the most expensive artists of India. During his lifetime, he produced very few artifacts and died in 2009. Apart from the sculptor, he was also a film maker.
\end{abstract}

Hindi : कालिदास और पद्म भूषण से सम्मानित अंतरराष्ट्रीय स्तर के प्रसिद्ध चित्रकार और मूर्तिकार तैयब मेहता के चित्रों में से अधिकांश बचपन में कई घटनाओं से प्रभावित रहे हैं, एडवर्ड मुंस और कोकशका ने अपनी कला में गुजरात के खेड़ा में पैदा हुए तैयब पर काफी प्रभाव डाला था। समय-समय पर शैली। लेकिन बदलाव देखा जाता है। प्रारंभिक चित्रों में, अभिव्यक्ति को स्थान दिया गया है, मध्यम स्तर के चित्रों में, अंतरिक्ष की अभिव्यक्ति को द्विभाजित दो-आयामी चित्र और खाली स्थान से बदल दिया गया है, विकर्ण ने अंतिम चित्रों में अपना स्थान लिया, जिसके तहत त्रिकोणों में चित्र बनाना शुरू किया। त्योहारों, काली आदि के साथ, उन्हें भारत के सबसे महंगे कलाकारों में गिना जाता था। अपने जीवनकाल के दौरान, उन्होंने बहुत कम कलाकृतियों का निर्माण किया और 2009 में उनकी मृत्यु हो गई। मूर्तिकार के अलावा, वह एक फिल्म निर्माता भी थे।

Keywords: Expression; Kasaeebaada; Trinale; Two-Dimesional; Minimalist Art; Ilham; Diagonal; Saffronart; PostImpressionism; Kudaal; Kemaald; Eyeta; Reintroduction. 


\section{1. प्रस्तावना}

"अन्तर्राष्ट्रीय सुप्रसिद्ध कलाकार तैयब मैहता अपनी खास शैली के लिए जाने जाते हैं आज के दौर में उनकी कलाकृतियाँ ऊँचे दाम में खरीदने के लिए लोग लालायित रहते हैं, जिसके कारण विश्व के कला बाजार में उनका एक जाना-माना नाम है।"

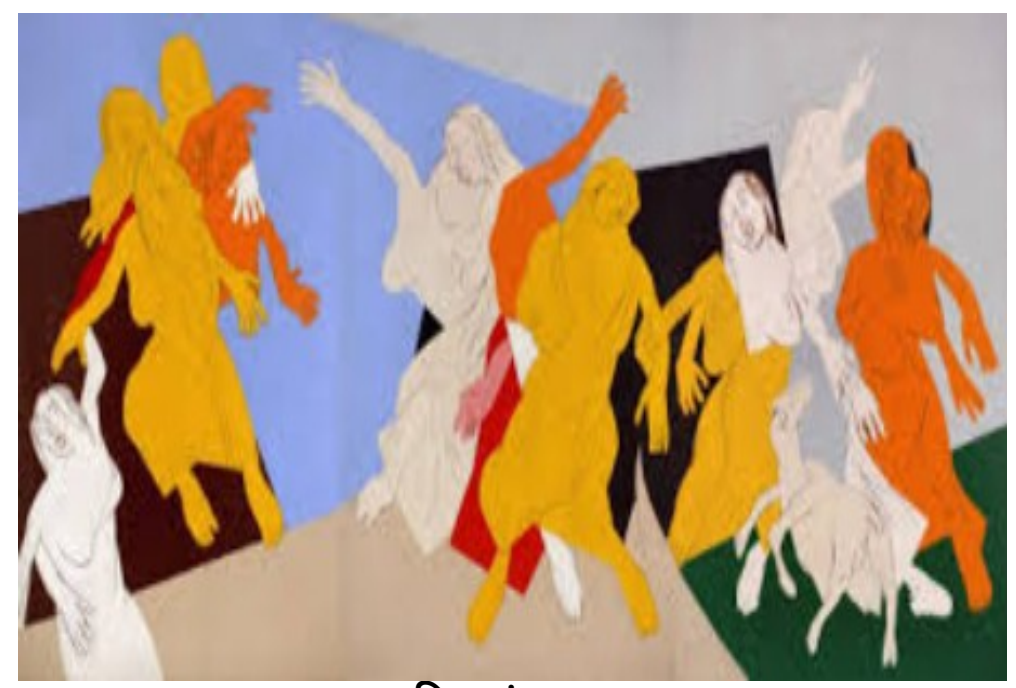

चित्र संख्या 1

भारत में कला और कलाकारों पर सन् 1947 के भारत विभाजन का प्रत्यक्ष और अप्रत्यक्ष रूप से प्रभाव पड़ा। यह प्रभाव तैयब मेहता की पेंटिंग में हिंसा पीड़ा के रूप में अभिव्यक्त होता है। वह अपने बचपन की एक घटना का जिक्र निक्की ताई टाॅमकिन्स सेठ से बात-चीत के दौरान करते हैं। वह कहते हैं कि विभाजन के बाद हुए दंगों में मुम्बई में एक व्यक्ति को पत्थर से मारने की घटना ने उनके हृदय पर गहरा आघात पहुँचाया। वह दोहराते हैं मेरे बचपन में ही हिंसा के तत्व थे। मेरे सामने की पीढ़ी अपना भाग्य बनाने के लिए जैसे ही धीरे-धीरे अपने समुदाय से बाहर निकली उसने एक स्थायी झंझट खड़ा कर लिया और मुझे स्मरण होता है कि मुहल्ले में वह हिंसक लड़ाई अनायास ही छिड़ जाती थी। एक घटना का मुझ पर गहरा असर हुआ। विभाजन के समय मैं मोहम्मद अली रोड़ में रहता था। वह लगभग एक मुस्लिम बाहुल्य इलाका था।[1] मैं स्मरण करता हूँ कि अपनी खिड़की के नीचे सड़क पर एक युवा व्यक्ति की हत्या होते देख रहा था। भीड़ ने पीट-पीट कर उसे मार डाला तथा पत्थर से कूच दिया। इस घटना के बाद मैं कुछ दिनों तक बुखार से पीड़ित रहा। वह छवि आज भी मेरे दिमाग में कौंधती है। लहू को देखते ही मेरा शरीर सुत्र पड़ जाता है और किसी तरह की हिंसा चिल्लाहट से भी।

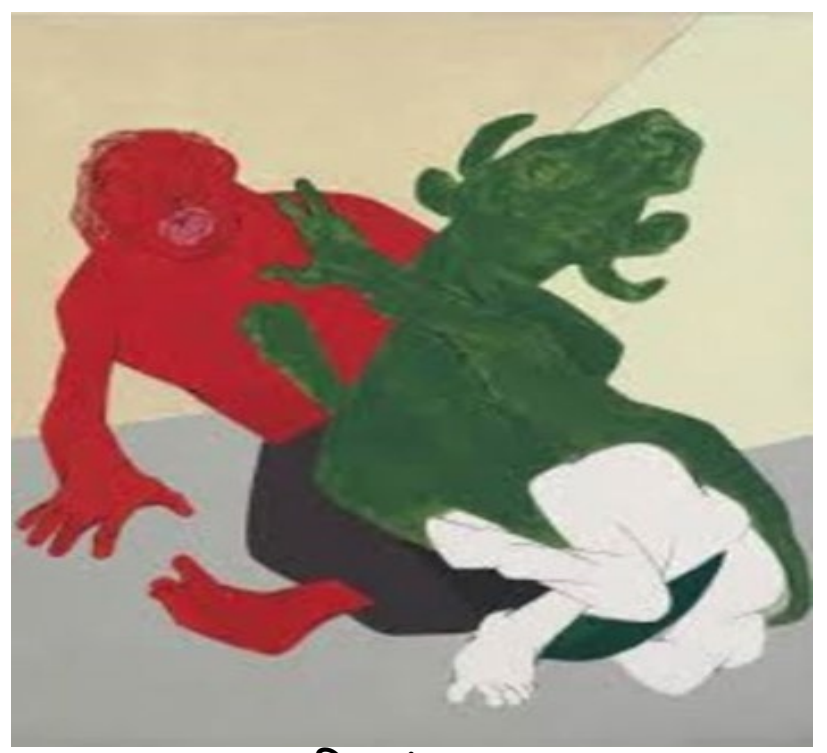

चित्र संख्या 2 
गुजरात के जिला खेड़ा में 26 जुलाई 1924 में जन्में तैयब मेहता का पालन-पोषण गुजरात के दाऊदी बोहरा समुदाय में हुआ था। उन्होंने सन् 1952 में सर जे०जे० स्कूल ऑफ़ आर्ट मुम्बई से कला में डिप्लोमा प्राप्त किया। इसके बाद वह सन् 1959 में लन्दन चले गये वहाँ अध्ययन के साथ-साथ प्रदर्शनियाँ भी करते रहे। वह सन् 1965 में फिर वापस भारत आ गये और यहाँ कई प्रदर्शनियों का आयोजन किया।

तैयब मेहता ने आरम्भिक चित्रों में अभिव्यक्ति को सबसे ज्यादा प्राथमिकता दी है, विकृत भयावह छवियाँ, भयानक रूप से विकृत खाल, उतरा हुआ माँस अभिव्यक्ति की पराकाष्ठा है। [2] तैयब मेहता कहते हैं मैंने चित्रकला की भाषा की समझ को विकसित नहीं किया था। अभिव्यंजना सीधे दर्शक पर असर डालती है। मुन्श, कोकोशका, एमिल नोल्डे चित्रकला की परम्परा के चित्रकार नहीं बल्कि ये ठोस आन्तरिकता के चित्रकार थे। मैं भी आन्तरिकता की चित्रकारी कर रहा था।

एडवर्ड मुन्श अपने चित्रों में तेज, चटक और चमकीले रंगों से अभिव्यंजना प्रस्तुत करता था और चित्रों को बहुत सादा बनाता था तथा रेखांकन बहुत बोल्ड था। उनमें भावभिव्यक्ति कूट-कूट कर भरी होती थी। 'चीख' (The Cry) शीर्षक लीथोग्राफी विश्व विख्यात है, जिसमें उसने पुल के ऊपर एक स्त्री को भय से चीखते हुए चित्रित किया है। इस चित्र में इतनी अधिक अभिव्यक्ति उसने भर दी है कि प्रेक्षक को स्त्री की करूणा चीख-पुकार बिना वाणी के सुनाई पड़ती है। अभिव्यंजना का यह अति उत्कृष्ट हृष्टन्त विश्व विख्यात है। वॉनगॉग और मुन्श से प्रेरित कोकोशका के व्यक्तिचित्रों में बोल्डली चित्रों का अंकन है। उनके चित्रों में तार के समान बारीक लाईनों, मृदुल वर्ण गहरे भावाभिव्यक्तिक के साथ प्रेक्षक से जुड़ती है। कोकोशका के चित्रों में चित्रकला की भाषाई समझ नहीं है। उसमें हृदय की गहराईयो से उकेरी हुई अभिव्यंजना है।

तैयब मेहता हमारी राष्ट्रीय दशा का बोध बँधे हुए साँड़ की विभिन्न छबियों में दिखाते हैं। बंधे हुए साँड़ के रूप में वे अपने समुदाय के कठोर नियमों, क्रिया-कलापों को भी बँधे साँड़ के रूप में अवगत कराते हैं। उनके समुदाये का ताना-बाना बहुत कसा हुआ था।

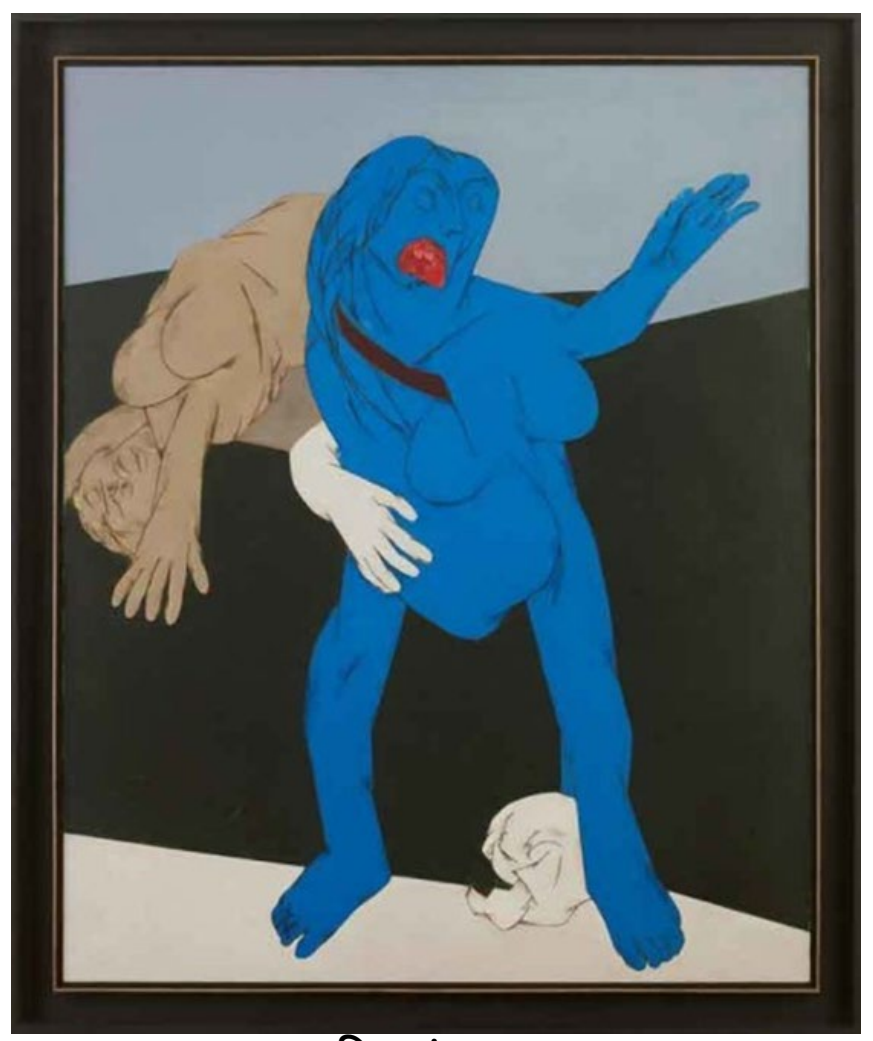

चित्र संख्या 3

तैयब मेहता कहते है[3] बाँधा हुआ साँड़ मेरे लिए अनेक स्तरों पर एक छवि की प्राप्ति के रूप में महत्वपूर्ण था। विशाल ऊर्जा के बयान के तौर पर बँधा अथव घेरा हुआ। जिस तरह वे किसी जानवर को काटने के पहले उसके पैरों को बाँधकर उसे कसाईबाड़े के फर्श पर पटकते हैं आपको महसूस होता है कि कोई बहुत महत्वपूर्ण चीज़ छूट गयी है। बाँधे हुए साँड़ से हमारी राष्ट्रीय दशा का बोध होता है। जहाँ मानव समूह अपनी विशाल ऊर्जा का सही दिशा में इस्तेमाल करने में असमर्थ है। शायद अपने समुदाय के बारे में भी मेरी अनुभूति, वह समुदाय जिसका ताना-वाना बड़ा कसा हुआ था, लगभग क्रूरता को स्पर्श करता है। 


\section{कुलविंदर कौर, डॉ अंजलि पांडे}

सन् 1968 में भारत में आयोजित त्रिनालें प्रदर्शनी में उन्हें पुरस्कार मिला, इस समय तैयब मेहता के चित्रों में एक अमूल परिवर्तन आ गया, तीक्षणता से बुनी गयी अभिव्यंजनावादी आकृति की जगह रंगों का बड़ा क्षेत्र अतिसूक्ष्म द्विआयामी चित्र एवं स्थान का एक सचेत विभाजन दिखायी देने लगे। यह परिवर्तन उनके अमेरिका जाने के बाद आया। वह सन् 1968 में ही राऍकफेलर फाउण्डेशन के तहत अमेरिका गये।रॉकफेलर फाउण्डेशन ने ही उनका सारा खर्च उठाया। इसलिए वह कला एवं अमेरिकी कला परिद्यश्य पर ध्यान केन्द्रित करने के लिए पूरी तरह स्वतन्त्र हुए।[4]

अमेरिका में तैयब मेहता ने पूरा एक साल का समय चित्रकृतियों को देखने तथा चित्रकारों से मिलने में लगाया। वह कहते हैं कि अतिसूक्ष्मवादी कला से मेरा सामना एक इलहाम की तरह था।[5] पहले मैं अतिसूक्ष्मवादी पुनप्ररस्तुतियों को देख चुका था, लेकिन मूल काम को नहीं देखा था। यदि मैंने मूल कलाकृतियों को नहीं देखा होता तो उनमे से अधिकांश को चतुराई जानकर एक और अन्य चतुर विचार के रूप में उन्हें हटा दिया होता, परन्तु जब मैंने उदाहरण के तौर पर पहला मूल वर्नान्ड न्यूमैन देखा तो मेेरे अन्दर इसके प्रति एक अविश्वसनीय भावात्मक प्रतिक्रिया हुई। कैनवास पर कोई आकृति नहीं थी, लेकिन जिस तरह रंगों का प्रयोग हुआ था, जिस तरह का काम किया गया था। सारा क्षेत्र सुनियोजित था। इसमें कुछ था जो अकथनीय है। भावना के स्तर पर यह आपको प्रभावित करता है। मेरी समझ से

यही वह अप्रत्यक्ष गुण है, जिसके बारे में हम बात कर रहे थे। यह एक प्रत्यक्ष प्रतिक्रिया है जिसकी आप सचमुच व्याख्या नहीं कर सकते हैं।[6]

\section{2. तैयब मेहता की पेंटिंग मे विकर्ण (डायगनल)}

सत्तर के दशक में तैयब मेहता के चित्रों में विकर्ण तत्व विशेष रूप से नजर आता है। तैयब मेहता कहते हैं, कि मैं कला में स्थान को परिभाषित करने के लिए कैनवास को सक्रिय करने के लिए मैं एक उपकरण ढूँढ़ने का प्रयास कर रहा था। यदि मैं केवल अपेक्षाकृत छोटे वर्गों या आयतों की प्रबलता ही सृजित कर पाता था, तो मैं केवल अपेक्षाकृत छोटे वर्गों या आयतों की प्रबलता ही सृजित कर पाता। लेकिन यदि कैनवास को किसी विकर्ण से काटता था तो इससे तुरन्त एक निश्चित विस्थापन हो जाता था।[7] दो सृजित त्रिभुजों के भीतर किसी तस्वीर को वितरित और विभाजित करने तथा स्वतः इसे तोड़ने और अलग करने के मैं काबिल हो गया था। फिर भी, विकर्ण केन्द्र से अलग एक प्रकार की एकता बनाए रखता था। वस्तुतः स्वयं में यह एक चित्रमूलक तत्व बन गया।

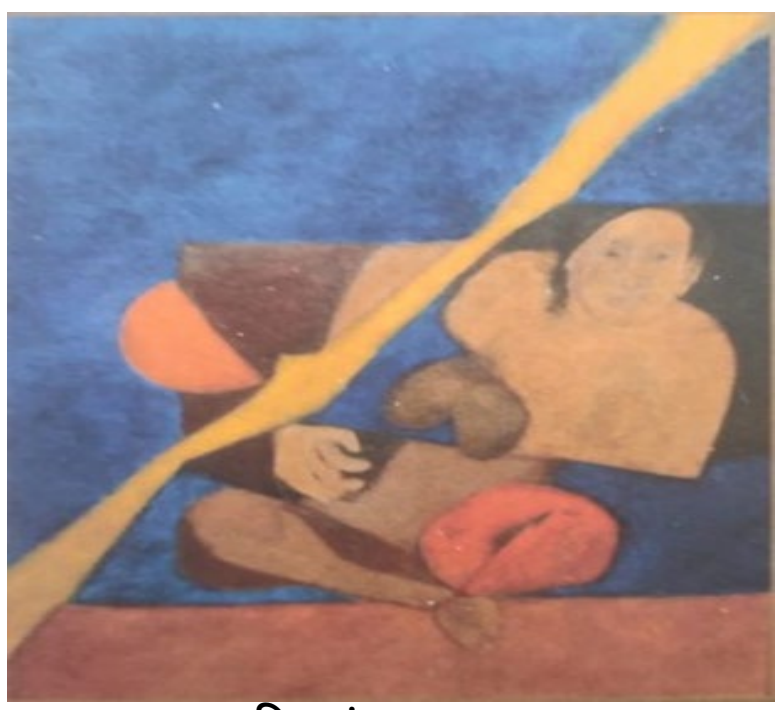

चित्र संख्या 4

तैयब मेहता ने 'उत्सव' चित्र की पृष्ठभूमि में कर्णवत रेखाओं से ब्लाक का निर्माण कर स्पेस का विभाजन किया। जिसमें भूरे, हल्के नीले, अम्बर, ग्रीन और ग्रे रंगों का प्रयोग किया गया, जिसमें नांरगी, पीली, सफेद महिलाओं को नृत्य की मुद्रा में चित्रित किया है। सभी पाश्र्वभूमि में सपाट रंगों का प्रयोग किया गया, विकर्ण द्वारा चित्र को तीन भागों में विभाजित किया गया है। नृत्य की मुद्रा में महिलाओं के साथ-साथ बकरी का चित्रण है। अन्तर्राष्ट्रीय स्तर पर सबसे अधिक कीमत पर बिकने वाली पेंन्टिग 'उत्सव' लगभग 15 मिलियन में नीलाम हुई, समकालीन भारतीय कलाकारों में सबसे महंगी पेंन्टिग बेचने वाले कलाकारों में से एक थे तैयब मेहता। भारत में हिन्दू देवी के रूप में पूजे जाने वाली काली जिसे बंगाल के लोग देवी के रूप में श्रृद्धा से पूजते हैं। तैयब मेहता ने देवी काली को एक्रेलिक रंगों से कैनवास 
पर चित्रण का माध्यम बनाया। इस चित्र की रचना 1997 में की और मई 2005 में भारतीय सैफ्रोनार्ट की ऑनलाइन नीलामी में 10 मिलियन (22.99 करोड़) भारतीय रूपये में बेचा, इस चित्र के पाश्व भाग में ग्रे तथा अम्बर कलर में नीचे सफेद तीन भागों में विभाजित किया है[8]। तैयब मेहता ने अपने कैनवस पर काली के चित्र को नीले रंग में चित्रित किया है, जिसका खुला मुँह व जीभ लाल रंग से दर्शाया है। चित्र में उत्तरप्रभाववाद की तरह फ्लैट रंगों का प्रयोग किया गया है।[8]

यह पेंटिंग मानवीय मन की दुविधा अच्छाई और बुराई की लड़ाई, सृजन और विनाश को लेकर अंतद्रवद्ध को दर्शाती है।

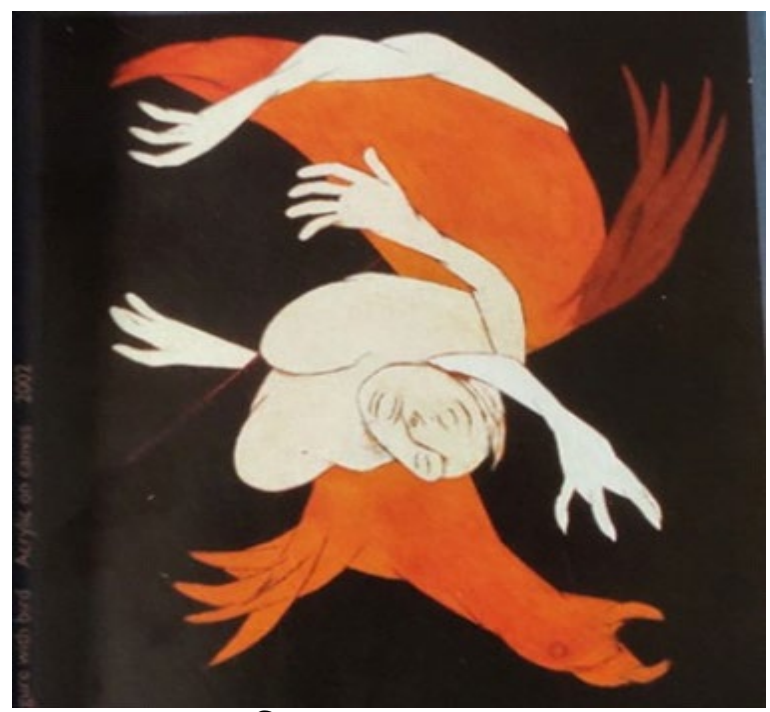

चित्र संख्या 5

तैयब मेहता अधिकांश अपने चित्रों में बहुलित अंग और वक्षस्थल का प्रयोग कैनवस पर उतार-चढ़ाव दर्शाने के लिए करते हैं ताकि चित्रों में सजीवता आ सके, क्योंकि उनके चित्रों में मानव आकृतियाँ होती हैं, मानव आकृतियों को लय व गतिशीलता प्रदान करने के लिए वह ऐसा करते हैं।

उनकी चित्रकृतियों में नारी चित्रों की प्रबलता होना केवल कैनवस पर उतार-चढ़ाव का एक साधन मात्र है। न की नर या नारी की छवियों से केवल आकृतियों को इस तरह से बनाया है जो देखने वाले का ध्यान उन पर आकर्षित, हो, फिर चाहे वह नर चित्र हो या नारी चित्र, वह कहते हैं नर अथवा नारी की छवियों से वास्ता होने से आशय है आपका चित्र में प्रवेश होना और लोगों द्वारा शीघ्र ही कृतियों में कहानियों का ढूंढ़ना, मानव चित्रण का बहुतायत मात्रा में होना, शुद्ध, अमूर्तन होने को दर्शाता है। छवियों को तोड़कर विभिन्न रंगों के प्रयोग मानव चित्रों को तैयब मेहता ने एक प्रकार की मोटरगाड़ी की तरह बताया है। वह न तो अतिसूक्ष्मवादी और न ही अमूर्त चित्रकार हैं उनके काम में अतिव्यंजनावादी लक्षण नजर आते हैं, मानव चित्रण उनका स्रोत है, जिसके प्रति आरम्भिक समय में उनके अन्दर प्रतिक्रिया थी,[9] लेकिन कैनवस पर उक्त छवि को लाने के क्रम में कैनवस के उतार-चढ़ाव , रंगों के क्षेत्र वितरण और दिशा विभाजन के बारे में सोचना शुरू कर देता हूँ। मैं एक प्रेक्षक के रूप में स्वयं तथा दृश्यमान वस्तु के रूप में कैनवस के बीच एक निश्चित दूरी बनाता हूँ ताकि चित्रित कृति अपनी इयत्ता हासिल कर सकें।

1969-70 में 'कुदाल' फिल्म बनाई जिसके लिए उन्हें 'फिल्म फेयर' पुरस्कार मिला। वे अमूर्त रूचि न रखते हुए स्वयं को अभिव्यंजनवादी कलाकार मानते हैं।

तैयब मेहता पूरे साल भर में दस कैनवस चित्रकृतियों को ही सृजित करते थे, यदि कोई कृति उनके मन को अच्छी नहीं लगती तो वह उसे नहीं रखते थे उस कृति को हटा देते थे। जब कभी एक ही कृति को उनके पास रखे बहुत दिन हो जाते तो वह उसे भी खत्म कर देते थे, तैयब मेहता की अन्तिम प्रदर्शनी[10] केमाल्ड मुम्बई के साथ 1976 में जहाँगीर आर्ट गैलरी मुम्बई में लगायी, तैयब मेहता अपनी प्रदर्शनियों में बहुतायत मात्रा में चित्रकृतियों को एक साथ नहीं प्रदर्शित करते थे, क्योंकि उनके पास एक साथ बहुत सारा काम इक्टा नहीं हो पाता था। तैयब मेहता का जीवन सादगी भरा था। उन्होंने मनमुताबिक चित्रों का सृजन कर, काम के बल पर अपनी पहचान बनायी ना कि प्रेसवार्ता, विज्ञापन या प्रोपोगैन्डा करके।

तैयब मेहता एक अच्छे चित्रकार, मूर्तिकार और फिल्म मेकर रहें। उन्हें सन् 1988 में ‘कालिदास' और सन् 2007 को पद्म-भूषण सम्मान से सम्मानित किया गया। वह भारतीय समकालीन कला के मार्तण्ड की तरह हैं। उनका अन्तकाल 2 जुलाई 2009 को हुआ। 


\section{कुलविंदर कौर, डॉ अंजलि पांडे}

\section{3. निष्कर्ष}

इस प्रकार हम कह सकते हैं कि कलाकार के मन मस्तिष्क पर सामाजिक घटनाओं का गहरा प्रभाव पड़ता है। तैयब मेहता इससे कैसे अछूते रह सकते हैं। उनके तीनों ही दौर के चित्रों में इसके साक्षात प्रमाण देखने को मिलते हैं, चाहे वह प्रारम्भिक दौर के चित्र हों जिनमें भावाव्यक्ति स्पष्ट झलकती है या मध्यम दौर के चित्र जिसमें अति सूक्ष्म द्वियामी और खाली स्थान विभाजन या फिर विर्कणता लिए हुए अंतिम दौर के चित्र हो। तैयब अपनी खास विषय और तकनीक के माध्यम से ही विश्व स्तर के कलाकारों में अपना स्थान रखते हैं। तैयब सामाजिक घटनाओं के अपने जीवन पर प्रभाव को चित्रों द्वारा प्रत्यक्ष रूप से प्रस्तुत करके अवगत कराते है और एक संदेश देते है कि कलाकार समाज का आईना है। यह कहना गलत न होगा।

\section{SOURCES OF FUNDING}

None.

\section{CONFLICT OF INTEREST}

None.

\section{ACKNOWLEDGMENT}

None.

\section{REFERENCES}

[1] Daiya Piyush : Kala Bharti (Volume - One, 2010), Lalit Kala Akademi, New Delhi, Pg. - 467

[2] Ibid : Pg. -468

[3] Bajpai Rajendra : Mordern Art, Sahitya Niketan Kanpur, Pg. - 69 4- $\quad$ Daiya Piyush : Kala Bharti (Volume One, 2010), Lalit Kala

[4] Akademi, New Delhi, Pg. - 468 5-

[5] Ibid : Pg. -468

[6] Ibid : Pg. -469

[7] Ibid : Pg. - 469-470

[8] Singh Priya : M.Patrika.Com, Published, 15 Jul 2018

[9] Daiya Piyush : Kala Bharti (Volume - One, 2010), Lalit Kala Akademi, New Delhi, Pg. - 470

[10] Ibid : Pg. -471 